\title{
Use of Piaget's theory in preschool nutrition education
}

\author{
Uso da teoria de Piaget na educação \\ nutricional de pré-escolares
}

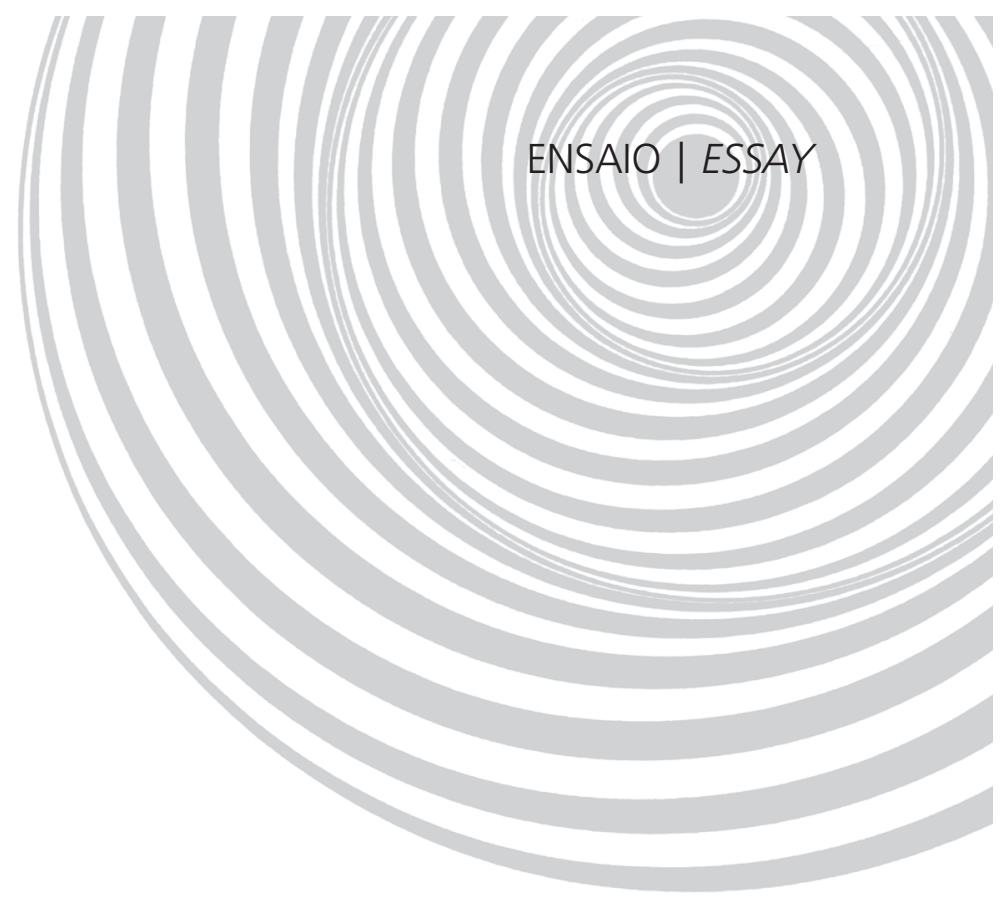

Hatice BAŞ KALE'

Zuhal BAHAR ${ }^{1}$

Günsel BAŞER ${ }^{1}$

Meziyet $A R I^{2}$

\section{A B S T R A C T}

The preschool period is a time when children learn many concepts and develop life-long habits. In that period, children learn about appropriate and balanced nutrition and acquire good eating habits for later years. Piaget determined that children's cognitive development is important for their understanding of and learning about the world around them. Piaget's theory can be used as a guide in nutrition education. In fact, it helps to design effective nutrition education appropriate for the developmental stages of childhood. The purpose of this article is to describe Piaget's theory and nutrition education based on this theory. This article will discuss how Piaget's theory is to be used in the development of nutritional habits of preschool children and will make an attempt to provide a viewpoint for those who provide nutrition education.

Indexing terms: Food and nutrition education. Child rearing. Child, preschool. Piaget.

\section{R E S U M O}

O período pré-escolar é uma época na qual a criança aprende muitos conceitos e desenvolve hábitos que persistem a vida toda. Nesta época, a criança aprende sobre nutrição adequada e balanceada e adquire bons hábitos alimentares para os anos seguintes. Piaget estabeleceu que o desenvolvimento cognitivo de uma criança é importante para a compreensão e o aprendizado do mundo que a cerca. A teoria de Piaget pode ser usada como um guia na educação nutricional. De fato, a teoria ajuda a elaborar uma educação nutricional apropriada para os estágios de desenvo/vimento infantis. O objetivo deste artigo é descrever a teoria de Piaget e a educação nutricional com base nesta teoria. Este artigo discutirá como a teoria de Piaget pode ser usada no desenvolvimento dos hábitos nutricionais de pré-escolares na tentativa de apresentar um panorama aos profissionais envolvidos com a educação nutricional.

Termos de indexação: Educação nutricional. Educação infantil. Pré-escolares. Piaget.

${ }^{1}$ Dokuz Eylul University School Of Nursing, Department Of Child Health Nursing. 35340, Inciralt1, Izmir, Turkiye.

Correspondence to/Correspondência para: H. BAŞKALE. E-mail: <hakkgul@gmail.com>.

2 Hacettepe University Faculty of Health Sciences, Department of Child Development. S1 hhiye, Ankara, Turkiye. 


\section{INTRODUCTION}

Nutrition is one of the basic needs of life. Nutrition education in the early years of life, particularly in the preschool period, is very important for an individual's health throughout life. Nutritional experiences at a young age influence nutritional habits in adulthood. For this reason, nutrition education should be continuous, effective and directed towards all family members. It should include the following stages: offering of education, acquisition of knowledge, formation of attitudes and behavior development. Parental eating habits have a direct or indirect effect on their children's eating styles ${ }^{1-3}$.

The preschool period is a time when children develop many habits likely to continue in adulthood. It is important that children not only acquire knowledge about appropriate and balanced nutrition, but also develop good eating habits.

However, the article will mainly focus on nurses since health and wellness of children are two important nursing concepts and nutrition is the key to health and wellness. In fact, it is important that nurses use appropriate educational methods while teaching children about nutrition ${ }^{4}$. Piaget's theory offers a precise definition of children's cognitive development, emphasizes a child-centered approach, underlines play and self discovery and provides guidance in the preparation of age-specific education contents. For these reasons, Piaget's theory was used to focus on nutrition education for preoperational children. The first purpose of this article is to plan nutrition education for preschool children based on Piaget's Cognitive Development Theory. The second purpose is to provide guidance for all those who give nutritional education to children, such as pediatric nurses, dieticians, child development specialists and preschool teachers, in designing nutrition education appropriate for the developmental stages of childhood according to Piaget's theory.

Nurses' knowledge about Piaget's process of cognitive development will play a major role in their attitude towards children. A nurse who has a good understanding of cognitive development in children is aware of a child's thinking patterns and the changes that occur during different developmental stages and can make use of this information to develop and maintain communication with children that are likely to play a role in a positive child-nurse relationship. It is important for nurses to learn the process of cognitive development in childhood as they plan nutrition education for children.

\section{Piaget and the cognitive development of the child}

Jean Piaget (1896-1980) was a biologist collector of mollusks. Later, he became interested in philosophy and psychology and studied the development of intelligence in children. Piaget's theory is based on his observations of mental development in his three children. He was a structuralist, genetic epistemologist who investigated the development of knowledge ${ }^{5,6}$. The only aim of Piaget's developmental psychology and genetic epistemology was to seek for an answer to the question of how knowledge increases ${ }^{7}$. Piaget explained the aim of genetic epistemology as follows:

"Genetic epistemology aims to study the origins of the various kinds of knowledge, starting with their most elementary forms, and to follow their development to later levels up to, and including, scientific thought. But though this kind of analysis involves an essential element of psychological experimentation, it must not be confused with a study in pure psychology" 5 (p.15).

In his studies on children aged 7-8 years, Piaget analyzed whole-part relationship (by asking children to put pearls together on a piece of string in accordance with a model), asymmetric relationships (by asking children to form sequences in accordance with a predetermined order) and harmonies between parts (by having children form sequences that complete each other). These analyses helped Piaget to understand why logical 
and mathematical operations are inseparable. In fact, children can understand processes through different ways, such as reversing and associating things with each other. Piaget sought the simplest functional structures and eventually found them in mental processes emphasizing conservation and permanence ${ }^{8}$.

Cognitive development is the name given to the intellectual processes that help individuals understand and learn about the world around them. The word cognition includes all of the mental activities related to thinking, knowing, problem solving, remembering and communicating. Cognitive development is the process of obtaining information from infancy to adulthood and includes the development of the mental processes that are used in learning. In cognitive development, there is always a continuous progress from spontaneous actions and reflexes towards desirable habits and intelligence. According to Piaget, the main problem is not the point where intelligence appeared, but to understand the mechanism of this progress. The mechanism is formed through assimilation. Individuals try to explain every new piece of information based on existing schemata $^{9-12}$.

Piaget also emphasizes the role of memory in cognitive development. Memory or remembering events/objects start at the same time as language. This is the period when children use semiotic thinking (using signs and symbols in language). Piaget stated that the most important factor in the development of memory is gradual organization. He defined memory like "the memory of the scheme is the scheme itself"13. The schemata are an organized thinking and behavior pattern. They are molds of behavior and thinking that are developed by children as they interact with their environment. Piaget defined schemata as "the structure or organization of actions as they are transferred or generalized by repetition in similar or analogous circumstances"13 (p.4).

According to Piaget, infants are born with schemata called reflexes. Children use their schemata in response to the new situations that they face. These behavioral styles are known as schematic perceptions. For example, a two-yearold child examines a ball in his or her hand, throws it on the floor, hits it with his or her foot and in this way has a direct relationship with the object as he or she tries to learn what it is useful for. In this way, the child learns that the ball is round and bounces, but the child will generalize the experience and think that all round objects will bounce. The stage of cognitive development that the child has reached can be limited to the child's personal experiences. New schemata are developed from changes in the child's observations as he or she interacts with other round objects (such as an apple or an orange) that do not bounce. Schemata continue to exist in proportion to the new information that is learned ${ }^{10,14,15}$.

Schemata are how children perceive objects. Children assimilate information from schemata. This information becomes established by changing schemata to accept new ideas. A birthday party can serve as an example. Some children associate birthday parties with cake, ice-cream, balloons and presents. When asked to recall what they ate at a party, they may automatically say cake and ice-cream even if they did not eat them. As children develop, their birthday party schemata may change. Different and more accurate events can form new schemata. The method of understanding and recalling food is based on children's schemata related to food items $\mathrm{s}^{4,10}$.

Children can acquire new knowledge through testing and making mistakes. An individual, in almost all stages of life, sees, hears and takes account of his or her past experiences; as Piaget says, the individual develops schemata about newly learned objects and ideas. Some of the things learned are formed internally as a consequence of useful reflections on thoughts rather than physical experiments. Thus, a child does not have to see many fruits or vegetables and can accommodate to the new concept by simply remembering what he/she has seen before ${ }^{11}$. 
In nutrition education, nurses can learn children's food schemata by asking questions about nutrition information. In addition, children's food schemata can be made concrete by asking them to draw a picture of their favorite food. To establish healthy and balanced nutrition schemata and healthy food groups on the existing food schemata, nurses.

- can create new food schemata in children's mind by showing them food or its photographs. These food schemata can include foods that the children have or have not previously seen;

- can read children stories about food and ask them which food was discussed in the stories or they have seen on television. Creating an appropriate environment for discussion, the educator can guide children and help them to remember food schemata and allow them to express themselves.

In this way, children also learn that there are different types of food, their food schemata are enriched and new food schemata begin to form. This helps children remember the food schemata they learned through social transmission.

Piaget attributed formation of mental structures to biological features. According to Piaget, intelligence is an adaptation. If one would like to define intelligence based on a relationship with life, it is a relationship between the organism and the environment. Genetic features also have an effect on intelligence. Piaget noted that although basic functions of thinking remains the same, various forms appear between children and adults. These forms, namely organization and adaptation, are important for mental development. Piaget determined that adaptation is used by children from the first stage of cognitive development. They adapt to the environment and changes in the environment by interacting with the environment. Development is an equilibriumdisequilibrium-new equilibrium process. For this process to be continuous, adaptation is necessary (9). Adaptation that exists in humans includes the processes of assimilation and accommodation 9,10,14,16. Piaget created a similar definition for intelligence:
Intelligence is assimilation to the extent that it incorporates all the given data of experience within its framework. Whether it is a question of thought which, due to judgment, brings the new into the known and thus reduces the universe to its own terms or whether it is a question of sensorimotor intelligence, which also structures things perceived by bringing them into its schemata, in every case intellectual adaptation involves an element of assimilation, that is to say of structuring through incorporation of external reality into forms due to the subject's activity ${ }^{9}$ (p.6).

Assimilation is necessary for the formation of mental structures and learning ${ }^{16}$. According to Piaget, assimilation "may be used to describe the action of an organism on nearby objects, in so far as this action depends on previous behavior involving the same or similar objects" 12 . Assimilation is defined as the classification or use of an object within the existing mental groups or processes. For example, a child who knows the meaning of dog calls cats and rabbits dog. However, when he/she assigns cats and rabbits in the appropriate category, it means that he/she has assimilated the concepts of cats and rabbits. When a child faces a new object and begins to use it, he/she assimilates the object. If the child has acquired the schemata of shaking and throwing an object, then he/she will use the same schemata with a new object. He/she will throw and shake the new object that he/she is given. In this way it is assimilated. A biological example of this is the digestion of food. Food undergoes changes in an organism. When food is eaten, it is separated into its minerals and is carried to other parts of the body through the blood stream. Food is assimilated by the digestive system. A child assimilates by putting new objects into existing groups. For example, a child who knows fruits and vegetables may classify food as fruit or vegetable and begin to use fruit and vegetables ${ }^{9,13,14,16-20}$. However, the child has to have physical and mental 
development and encounter these foods through social transmission and experiences.

Piaget mentioned assimilation in his tests with his daughter Jacqueline (observation 182):

Observation 182. At 1;8 (30) Jacqueline has an ivory plate in front of her, pierced by holes of 1-2 $\mathrm{mm}$. in diameter and watches me put the point of a pencil in one of the holes. The pencil remains stuck vertically there and Jacqueline laughs. She grasps the pencil and repeats the operation. Then I hold out another pencil to her but with the unsharpened end directed toward the plate. Jacqueline grasps it but does not turn it over and tries to introduce this end (the pencil is $5 \mathrm{~mm}$. in diameter) into each of the three holes in succession. She keeps this up for quite a while even returning to the smallest holes. When I return the first pencil to Jacqueline, she puts it in the hole correctly at once. When I hand it to her upside down, she turns it over even before making an attempt, thus revealing that she is very capable of understanding the conditions for putting it in. On the other hand, when I hold out the second pencil correctly directed (the point down,) she also puts it in by the point. But if I offer it to her upside down, she does not turn it over and recommences wishing to put it in by the unsharpened end. This behavior pattern remained absolutely constant during thirty attempts, that is to say, Jacqueline never turned the second pencil over whereas she always directed the first one correctly. At about the thirtieth attempt, Jacqueline suddenly changes methods. She turns the second pencil over as she does the first and no longer tries a single time to put it in by the wrong end. If the series of these new attempts is compared with the first series, one has the impression of a sudden understanding, as of an idea which arises and which, when it has suddenly appeared, definitively imposes itself. In other words, the second pencil has suddenly been assimilated to the first. The primitive schema (connecting the two pencils by contrast) has dissociated itself and the pencil which one did not turn over has been assimilated to the particular schema of the pencil that one had to turn over. This kind of a process is consequently again capable of making us understand the mechanism of invention ${ }^{9}$ (p.345).

In nutrition education, nurses introduce children to food groups and have children use these foods in games so children will have assimilated the food groups. To do this:

a) Foods are classified and taught.

b) The food pyramid (Figure 1) is used to explain what needs to be eaten from which food groups for healthy nutrition.

c) Nurses show a picture of the food pyramid and use the characteristics of Piaget theory in which an idea is made concrete.

d) Abstract words such as protein, nutritious, healthy, unhealthy and diet should not be used to introduce important food groups. Nurses need to use the phrases "food we eat every day" and "food we eat occasionally" instead of using phrases such as "healthy/unhealthy" and use phrases such as "food that helps us grow and get strong" instead of "nutritious."

e) Nurses can make a puzzle from the food pyramid for children. To do this, the food pyramid that has been shown to children is divided into parts. Children are asked what food they have in their hands and to which food group it belongs. Then, children can put that food in the appropriate place in the food pyramid. For example, they can be asked to put a puzzle piece from the fruit group in the fruit group of the pyramid. Children see foods in the food pyramid and begin to increase their knowledge about foods. In addition, food models that belong to each group of food are shown, distributed and asked to which group they 
$910 \mid$ H. BA Ş KALE et al.

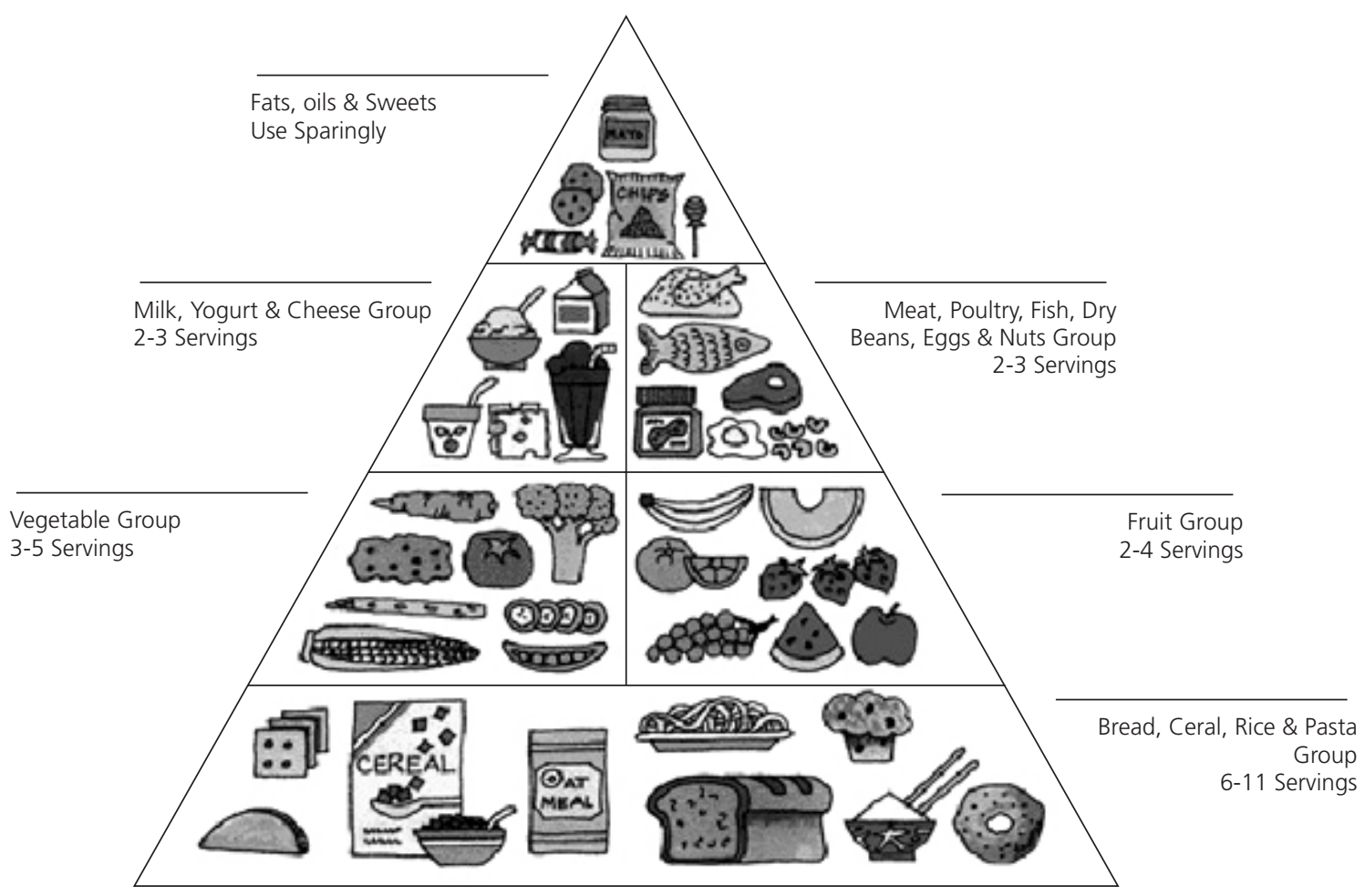

Figure 1: Food Guide Pyramid.

Source: Food Guide Pyramid ${ }^{34}$.

belong. It helps children assimilate their education, organize food information themselves and use autonomy.

f) Nurses give children a picture of a food from every group and ask them to color it. Here children have fun and see the picture closely which will help to transfer it into the long-term memory and increase food recall. Children color the food pictures in whatever color they want.

It should be kept in mind that children should show interest in education and should be willing to participate so that they can make assimilation. Therefore, it is important for Piaget's theory to be used in education. The educator plays a key role in it. According to Piaget, the educator should provide guidance in class, arrange the classroom environment in accordance with the child's development and make it interesting, to enable children to play an active role in their own education, draw children's attention and increase their motivation'. In fact, Piaget noted that when a schema was formed, it was spontaneously assimilated and adapted. Thus, children are motivated. This learning does not require any special reward, it occurs spontaneously.

By forming new schemata or changing the characteristics and scope of existing behavioral schemata, children accommodate to newly acquired information. In other words, assimilation results in the revelation of new ideas and different behaviors that are not consistent with the previously formed behavior ${ }^{6}, 13,17-21$. Nurses will replace children's existing schemata with newly learned foods that were drawn and new food information and will see them accommodate to the new situation.

Nurses can ask children to glue food pictures that they painted on the appropriate place on the food pyramid. Thus, children recognize that foods can be different things. Nurses can help children accommodate by gluing the pictures in 
the right places. As a result of assimilation and accommodation, children will adapt to the new nutrition concepts with experience and adaptation.

The foods used in education should be available in the given culture since even if a child assimilates a food unavailable in his/her culture, he/she may not be able to purchase it due to its high costs. For example, fruits such as mango and avocado, which Turkish people are not familiar with, are not readily obtainable or cheap. For these reasons, accommodation will not occur.

As a result of the interaction between assimilation and accommodation, the process of equilibrium occurs. Newly formed equilibrium is not static, but dynamic. Since the environment is constantly changing and there are things to be learned, the equilibrium is continuously disturbed and reformed. Otherwise, learning and development cannot not occur ${ }^{10,12,14}$. The term equilibrium also explains the development of intelligence ${ }^{6}$. Suction schema in infants exemplifies the understanding of Piaget's concepts. Babies make use of suction schema for many objects. They suck their bottles, thumbs, pacifiers, ears of toy bears and toy birds made of plastic. Some of these objects, such as bottles, thumbs and pacifiers, are more appropriate for the schema of the objects that could be sucked and babies' reaction to these objects may involve assimilation rather than adaptation. Thus, the schema of the objects that could be sucked remains unchanged and babies associate or assimilate new objects with this schema. When a child wants to suck the wings of his/her plastic toy bird, the wings of the bird may feel hard, may not be delicious and may be too big for his/her mouth. As a result, the child has to change his/her schema; namely, change the object that can be sucked and those that cannot be sucked, or may give up his/her schema. At last, the child achieves accommodation. During the course of adaptation to the new schema, the child will hit or kick the bird, which will mobilize the bird, and try to have fun. Later, when he/she picks up the bird and repeats these actions, formation of equilibrium will be observed ${ }^{9,10,13}$.
According to Piaget, each new thing disturbs the equilibrium for the child and the equilibrium is reformed through assimilation and adaptation. Thus, based on the process of discovering and understanding, behaviors are reorganized. As a consequence, attempts to know and understand the world in order to survive will cause formation of new schemata, achieve assimilation and adaptation and, in turn, organize the things learned ${ }^{11}$.

For the equilibrium process, nurses can have children cut up paper and tape it together to make a fruit calendar. In this way children will be more willing as a result of the activity that they did. Nurses can ask children to draw pictures of the fruit that they ate for one week on the calendar. The objective of this hands-on activity is to encourage children to learn through their own experiences. As a result, children develop new positive schemata related to fruit. In addition, at the end of the education, nurses can ask children to draw foods. They can be compared with the pictures drawn at the beginning of the education. Nurses will realize that children have new information about food and have changed their existing schemata with more healthy food schemata they have just learned.

When children learn to differentiate fruit from vegetables, they are thought to acquire more beneficial information compared with what they already know. They have learned more objects that are right to eat. In this way they find equilibrium by counteraction of disequilibrium with assimilation and accommodation. Nutrition education and relevant activities (drawing, playing reading, discussion, hands-on activities) together with information that children already have will help to form desirable nutrition concepts. Children add new knowledge to their previous knowledge through new activities and new learning experiences ${ }^{9}$. Acquiring a new nutrition concept takes place through the combination of the processes of assimilation, adaptation and equilibrium. Nutrition education helps children increase what they know about nutrition and 
change their behavior. New schemata acquired by children indicate effectiveness of education. In conclusion, nurses should give children nutrition education based on Piaget's theory at an early age so that it will have a lasting effect on their eating behavior.

\section{Factors affecting cognitive development according to Piaget}

Piaget determined that the factors affecting cognitive development were maturation, experience, and social transmission. When offering nutrition education, nurses should keep in mind that maturation, culture and experience affect the cognitive development of children.

Maturation: cognitive development occurs with maturation. As a result of maturation, physical development, language development and intellectual development occur. Maturation refers to experiences gained as a result of the things that happen to an organism as well as biological development. Accordingly, the child interacts with the environment during the learning process and self-development. The composition of interactions helps the child change his/her reactions in the form of reflexes into conscious behaviors shaped by environmental stimuli 10,13,14.

According to Piaget, maturation is associated with physical growth. Intelligence has a genetic component in the course of growth and development. Piaget noted that, like the learning ability, human intelligence and language is a result of maturation. Maturation is most marked in babies and young children since they grow rapidly. If a child's muscle and nervous systems are not well developed, he/she cannot know fruits and vegetables. Although maturation is important for development, it is not the only factor. There are cultural, physical and social factors which cause considerable differences in the levels of mental development $t^{9,11,13}$.

Experience: experience is forming relationships directly with objects. According to
Piaget, forming relationships with objects helps to gain two types of experience, namely, physical and logical and mathematical. In the physical experience, children learn physical characteristics of objects. While seeking for the answer to the questions beginning with "why", children start causal explanations. The latter enables the child to access to knowledge through an internal organization of their actions. In the logical and mathematical experiences, children can perform elementary inferences to classify spatial configurations and set up correspondences. Children develop as a result of interacting with experiences and their environment. Without classification, children cannot learn the color of objects and create knowledge. For example, children should see fruit and corresponding symbols at the same time so that they can associate fruit and the symbols representing fruit and should put them in the group of fruit or edible food $5,10,13,14,21$.

Social transmission: social transmission includes all that children learn from their mothers, fathers, friends, teachers, books and magazines. It is the culture of the society in which the individual lives. All societies have certain features typical of themselves and the cognitive development of all individuals has universal features. An example of learning with social transmission is information about nutrition learned from the family and television. When children hear a word which they are not familiar with or which is inconsistent with their prior knowledge, they move away from their prior equilibrium. Soon they start to seek higher-order equilibrium. Even though social transmission is necessary and important, it is not sufficient on its own. For social adaptation, first of all, language development is required ${ }^{8,13,14}$.

It is important for nurses who will give nutrition education to assess a child's maturation process. In fact, if a child's physical and language development is not adequate, interaction with the environment will be inadequate and the educational method that is used will not be effective.

Nurses who know the results of children's interactions with experience and their environment 
assess past experience before giving nutrition education and increase children's interactions with the environment. In addition, nurses need to know what children have learned through social transmission. Nutrition education should be based on evaluations of families' food culture and children's nutritional habits.

Equilibration: It is the term which combines three factors mentioned before: maturation, experience, social transmission. This term reflects an inborn tendency of thoughts which increasingly gets more balanced, meticulous and consistent in social relations. According to Piaget, equilibration is a process during which children, using the things they have assimilated before, acquire the appropriate behavior for a given situation. This equilibrium is not static. Children are effective and venturesome. A newly created equilibrium will be disturbed by outer factors and children's activities and will be recreated in a higher order. When children have learned to distinguish fruits from vegetables, they have obtained a more beneficial way of thinking compared to the way of thinking in the past. From then on, they identify a higher number of edible things more accurately. Thus, they create an equilibration and are less willing to turn to their prior way of thinking $9,11,13,14$.

In contrast, disequilibration is a discrepancy between what an individual encounters and what an individual knows. It forces an individual to accommodate newly encountered things into the existing schema or to create a new schema to achieve cognitive balance. Piaget noted that cognitive activity brings about learning 5,11,13 .

According to Piaget, children undergo four different stages to achieve adult thinking and knowledge (mental development). These are sensorimotor, preoperational, concrete operational and abstract operational stages. Each stage is built onto the previous one and helps to evolve a new level. Piaget found that all children go through these stages in order, but the speed at which they go through them differs. A child cannot skip a stage to go to the next stage. The age when children enter and complete a stage may differ with interaction of intelligence and social environment ${ }^{10,13,21}$.

In this article, Piaget's preoperational stage of cognitive development in two- to seven-yearold preschool children will be discussed in detail. During this stage, children have not yet developed logical thinking necessary to do specific operations. Language development is rapid. Children who begin to understand the relationship between an object and the word that represents it quickly discover the world around them. Piaget determined that cognitive development occurs during the process of gaining experiences since childbirth and maturity,5,20,21. It is clear that this process occurs when babies socially interact with their environment ${ }^{11}$.

Preoperational children are not yet fully developed cognitively. They have begun to acquire the ability to think. This is the stage in which children learn basic concepts. Pre-operational children learn by imitating, investigating, asking questions, comparing and classifying the things around them. At this age, symbolic play is frequent. For example, they can use rulers as guns or a rod as a horse, or cook with an imaginary cooker. Children may show their conflicts through symbolic plays and achieve their equilibration. The cognitive objective of language and dramatic play is symbolic representation. Piaget emphasized the role of symbolic play in emotional and social as well as cognitive development of children ${ }^{13,16}$. Children learn concepts more quickly and easily when they do activities themselves. For example, children are encouraged to participate actively in a game as they take on the role of a fruit by having a symbolic picture of that fruit hung around their neck. Hand skills develop physically as children touch, feel, look, compare, turn and throw. They observe and imitate their teachers, parents and other children ${ }^{16,20-22}$. According to Piaget, children are not passive learners. They have an active role in acquiring knowledge. Educators should keep in their minds that not all children are in the same cognitive stage. When putting a theory into practice, educators should devise group work in 
which all children can actively participate. For this reason, it is important for nurses to get children to take an active role in the nutrition education they will provide. Children learn better by doing something. Games which allow children to imitate things, to be physically active and to use objects may facilitate learning in the pre-operational period. Children need to be encouraged to abandon egocentrism and share and cooperate. Written materials need to be of the visual type, such as graphics and pictures $8,10,16,20,23,24$.

Explanations, classifications and demonstrations can be used to have children remember what they have learned. An educator ${ }^{4}$ determined that there are some points and guidelines that need to be kept in mind when preparing educational material according to Piaget's theory. They can be listed as in the following:

- An appropriate typeface (such as Comic Sans) and large font (14-point font) attracts children's attention and makes it easier for them to remember.

- Cultural foods (the foods most commonly eaten in the society) need to be kept in mind when choosing foods for appropriate target groups and selections. This will improve memory.

- Improving visual memory is very important for storing foods to be eaten in the long-term memory.

Nutrition education can be difficult in the preoperational stage (2-7 years). Children may not understand what is explained to them about nutrients and the relationship between nutrients and food. They may not understand the effects of food on the body, either. When adults explain nutrition and health to children, they use words like vitamins, minerals, nutritional food, digestion and risk of illness. It is difficult for children in the preoperational stage to understand and explain abstract concepts like the definition of health or the importance of nutrition. In the preoperational stage, children consider themselves healthy if they can laugh, walk and run ${ }^{22,25,26}$. For this reason, when the importance of nutrition is explained to children in the preoperational stage, instead of abstract nutritional concepts (such as nutrients that cannot be seen or touched like vitamins, minerals, proteins, and nutrients' effect on health and growth), concrete statements should be used, and concrete nutritional examples should be given. Colorful photographs of foods can be helpful. The messages in nutrition education need to be simple and positive and focus on behavior. Children in the preoperational stage cannot understand digestion or how nutrients affect the body. They would say, "Small pieces of carrot go to my arms and my legs." Instead of expressions like healthy food/unhealthy food, the phrases, "foods eaten every day" and "foods eaten sometimes" need to be used ${ }^{26}$. A nutrition education program based on Piaget's ideas provides children with many opportunities to discover objects and their environment. For example, many objects, experiences, such as drawing a picture and games that include nutritional activities, can be used to introduce five-year-olds to the concept of nutrition. Children learn by discovering their environment. The learning environment should allow children to use their senses, include drawing objects classified according to shape, color, number and form and have them participate actively in learning. A teacher who creates this learning environment observes, asks questions and provides guidance, but does not lecture or demonstrate ${ }^{11,15}$.

Children do not think less than adults, but they think differently. For example, the conservation concept is undeveloped and thoughts are irreversible in preoperational children 5,10,15-17,24,26. A child cannot infer the thought, "if I eat a lot, I will get fat" into the thought, "if I do not eat a lot, I will not get fat." Animism is another characteristic of this period. Children cannot distinguish between living and non-living things. This chaos is called animism. According to Piaget, kindergarten kids believe that stones are animate and that trees think (magic thought) 11,21,24.

Piaget noted that 7-8-year-olds can make classifications operationally. Younger children 
attempts to make classifications, though they are more primitive. Four-five-year-olds can classify such patterns as circles, squares and triangles made of paper into groups according to their geometric forms ${ }^{15}$. These features affect lack of acquisition of conservation. Suppose there are two glasses containing the same amount of milk and you pour milk into a long, thin glass and the other into a large in front of a child." Since the milk in the long, thin glass appears to reach a higher level of the glass, the child will tell you that glass contains more milk ${ }^{5,12}$. Even if you prove the opposite, he/ she cannot understand. In other words, the child has not acquired logical thinking yet. The child is under the influence of his/her perceptions rather than having logical thinking because he/she lacks the cognitive ability to understand the cause-effect relationships of the event. Piaget defined perception as in the following:

"Perception is the knowledge we have of objects or of their movements by direct and immediate contact, while intelligence is a form of knowledge obtaining when detours are involved and when spatial and temporal distances between subject and objects increase" 12 .

This stage is called preoperational since children do not have the cognitive ability to conduct operations. A characteristic that needs to be kept in mind when teaching children the classification of food groups is not to use many aspects to arouse the children's interest, but to concentrate on one aspect, such as color, shape or contents of the food product ${ }^{8,13,22,24,26}$. In nutrition education, it is important for nurses not to teach many characteristics of a food at a time but to explain only one characteristic, such as color or food group. For example, it can be difficult for preoperational children to learn that a banana is both a fruit and yellow in color at the same time.

Piaget's theory is not just used in nutrition; it has also been used in many other types of studies $^{27,28,29}$. Gorelick \& Clark ${ }^{30}$ implemented a nutrition education program to 187 three- to five-year-old children assigned into experimental and control groups in schools. The program included growing and preparing food, developing cognitive skills, encouraging creativity and preparing nutritious snacks. The classes were divided into two experimental and two control groups and every group had 46-47 children. The program contained 12 nutrition education activities. The children were asked to define foods, to classify foods (fruit-vegetable), to match food pictures, and to show pictures of what should be done before and after eating (show a picture of soap before eating and a toothbrush after eating). The results showed that three- to five-year-olds could easily define foods. The children's posttest nutritional knowledge score was higher on defining food. Gorelick \& Clark determined that using developmentally appropriate materials and activity-based learning experiences facilitated the measurement of the development of food and nutrition concepts ${ }^{30}$.

Lee et al..$^{31}$ gave an eight-week nutrition education to 60 three and half- to five-year-old children. Twenty children were taught in the development laboratory, 20 were taught in their homes by their parents and 20 children were the control group. During the education, food profile cards that had pictures of the food and its name were used. At the end of the education, the children were able to use cards that had pictures of food and graphs (graphs of vitamins A and C and calcium). It was concluded that the children offered education in the classroom learned better than the children taught at home and the control groups. Nutrition education was shown to increase the children's understanding of the concepts of health and illness ${ }^{31}$.

Singleton et al. ${ }^{32}$ investigated the role of nutrition in 60 four- to seven-year-olds perception of health. A four-week education program on the prevention of heart disease and improving health was offered. The children were evaluated though six open-ended semi-structured and 11 closedended questions done during 15-minute interviews. The investigators made a concept map based on the results of the interviews. Education was found 
916 | H. BA Ş KALE et al.

to increase the children's understanding of the relationship between health and nutrition ${ }^{32}$.

Auld et al. ${ }^{33}$ also used Piaget's theory as the basis of a nutrition education program. In a quasi-experimental study, class activities were implemented, teachers were interviewed and the food leftovers were observed. At the end of the study, the students in the experimental classroom had an increase in their knowledge, self-confidence in food preparation and consumption of fruits and vegetables. The authors suggested that education theories can be used for behavior changing ${ }^{33}$.

Based on the results of the studies reviewed, nutrition education based on Piaget's theory is effective. However, further studies using Piaget's cognitive development theory are needed to reveal the effect and reliability of the theory.

\section{CONCLUSION}

Piaget's cognitive development theory has been selected as a theoretical framework for the nutrition education guidance of preschool children. This theory provides a philosophical explanation of using knowledge, development and cognitive processes. The theory proposes that there should be a bridge between cognition, learning and behavior. Piaget's theory allows us to understand children's cognitive development and how and when they learn things. The preschool and school periods are important stages where children start to learn concepts and learn about their environment. Especially considering that preschool children do not have sufficient cognitive development, education offered at this age should be appropriate for their cognitive development ${ }^{30}$. In fact, education not suitable for a given stage may have a negative impact on children.

Piaget's theory offers ways to teach effectively and guides us in designing education programs. Children and their families need information about nutrition and other topics. Using the stages involved in the theory -schema, adaptation and equilibration- helps us make associations between the selected topics. It also helps planning education which encourages children to be active and creative and self-learning . When nurses prepare education programs which encourage thinking and learning, they should be aware of the cognitive developmental stages of the children. For example, a nurse who knows that simple, concrete and correct expressions should be used when talking to children under seven years old can communicate more easily and effectively. Therefore, the results of this review will provide guidance for nurses dietitians and other professionals who plan nutrition education for preschool children. It is recommended that nurses carry out studies that determine behavior changes regarding nutrition and other areas by using Piaget's Cognitive Development Theory.

\section{COLLABORATORS}

H. BA ŞKALE was responsible for the study conception and design and was responsible for the drafting of the manuscript. Z. BAHAR encouraged the writing of this review. G. BAŞ ER encouraged the use of Piaget's theory in nursing and nutrition education. All the authors made critical reviews to the paper and helped organize the review.

\section{R E F E R E N C E S}

1. Glenny AM, Meara SO, Melville A, Sheldon TA, Wilson $C$. The treatment and prevention of obesity: a systematic review of the literature. Int J Obes Relat Metab Disord. 1997; 21(9):715-37.

2. Dietz W. H. Overweight in childhood and adolescence. N Engl J Med. 2004; 350(9):855-7.

3. Moestue H, Huttly S, R. Sarella L, and Galab, S. 'The bigger the better': mothers' social networks and child nutrition in andhra pradesh. Public Health Nutr. 2007; 10(11):1274-82.

4. Hardy LR. Psychometric testing of a developmental food frequency questionnaire for elementary school children In North Carolina [dissertation]. University of North Carolina; 2002.

5. Piaget J. The Principles of genetic epistemology. London: Routledge \& Kegan Paul; 1972. Chapters 1-2.

6. Piaget J. Structuralism. London: Routledge \& Kegan Paul; 1971. Chapters 4-6. 
7. Smith L. (1997). A brief biography of Jean Piaget. [cited 2009 Mar 22]. Available from: <http://www. piaget.org/aboutPiaget.html>.

8. Evans RI. Jean Piaget: man and his ideas. Birinci Baskı, Ankara: Doruk Yayincilik; 1999. p.32, 125, 141, 149, 177-8.

9. Piaget J. The origins of intelligence in children. New York: International Universities Press; 1952. p.1-7, 35, 42, 157, 345, 381.

10. Atkinson C. Making sense of Piaget. London: Routledge \& Kegan Paul; 1983. Chapters 1-2, 6.

11. Yeșilyaprak B. Educational psychology, development, education and teaching. Ankara: PegemA Yayncilik; 2007. p.83, 86, 87, 94, 96.

12. Piaget J. The psychology of intelligence. New Jersey: Littlefield, Adams \& Co; 1960. Part 1-3.

13. Piaget J, Inhelder B. The psychology of the child. 2nd ed. New York: Basic Books; 1969. Chapters 2-3.

14. Phillips J. Piaget's theory: a primer. San Francisco: Freeman and Company; 1981. Chapter 1.

15. Piaget J. Genetic epistemology. Ankara: Sevinç Matbaası; 1984. Chapters 2-3.

16. Piaget J. Play, dreams and imitation in childhood. London: Routledge; 1999. Chapters 1-3.

17. Flavell JH, Miller PH, Miller SA. Cognitive development. New Jersey: Pearson Prentice Hall; 2002. Chapters 1, 5.

18. Webb P. Piaget: implications for teaching. Theory Pract. 2001; 19(2): 93-7.

19. Saler G, Edgington CG. Piaget webquest [cited 2007 Nov 29]. Available from: <http://pt3.nl.edu/ saleredgingtonwebquest.pdf>.

20. Duckworth E. "The having of wonderful ideas" and other essays on teaching and learning. $2^{\text {nd }}$ ed. New York: Teachers College Press; 1996. Chapters 2,8 .

21. Crain W. Theories of development: concepts and applications. New Jersey: Pearson Prentice Hall; 2005. Chapter 6.

22. Contento I. Children's thinking about food and eating-A piagetian-based study. J Nutr Educ. 1981; 13(Suppl.1):S86-S90.

23. Rickard KA, Gallahue DL, Gruen GE, Tridle M, Bewley N, Steele K. The play approach to learning in the context of families and schools: an alternative paradigm for nutrition and fitness education in the $21^{\text {st }}$ century. American Dietetic Association. J Am Diet Assoc. 1995; 95(10):1121.

24. Piaget J. Judgement and Reasoning in the Child. Ankara: Palme Yayincilik; 2007. p.165, 181, 231, 241, 279.

25. Breakwell ME. The association between parenting practices of parents of preschool children and the preschool children's nutrition knowledge [dissertation]. Toronto, Canada; 1991.

26. Wisconsin Nutrition Education Program. Developmentally appropriate nutrition education for youth ages 6-11. 2001 [cited 2007 Oct 12]. Available from: <http://www.uwex.edu/ces/wnep/ files/03resyth.pdf>

27. Smith L. Callery P. Children's accounts of their preoperative information needs. J Clin Nurs. 2005; 14(2):230-8.

28. Holzheimer L, Mohay H, Masters IB. Educating young children about asthma: comparing the effectiveness of a developmentally appropriate asthma education video tape and picture book. Child: Care, Health Dev. 1998; 24(1):85-99.

29. Pasnak R, Cooke WD, Hendricks C. Enhancing academic performance by strengthening classinclusion reasoning. J Psychol. 2006; 140(6): 603-13.

30. Gorelick M, Clark A. Effects of nutrition program on knowledge of preschoolchildren. J Nutr Educ. 1985; 17(3):88-92.

31. Lee TR, Schvaneveldt JD, Sorenson AW. Nutritional understanding of preschoolchildren taught in the home or a child development laboratory. Home Econ Res J. 1984; 13(1):52-60.

32. Singleton JC, Achterberg CL, Shannon BM. Role of food and nutrition in the health perceptions of young children. J Am Diet Assoc. 1992; 92(1): 67-70.

33. Auld GW, Romaniello C, Heimendinger J, Hambidge C, Hambidge M. Outcomes from a school-based nutrition education program using resource teachers and cross-disciplinary models. J Nutr Educ. 1998; 30(5):268-80.

34. Food Guide Pyramid. [cited 2008 Mar 10]. Available from: <http://www.diabetesdiabeticdiet.com/ food_pyramid.htm>.

Received on: 17/9/2008

Final version resubmitted on: 15/4/2009

Approved on: 7/7/2009 